\title{
An open letter to Colonel Muammar al-Gaddafi
}

Dear Colonel Muammar al-Gaddafi,

We, Nobel Laureates in the sciences, are gravely concerned about the ongoing trial of five Bulgarian nurses, Valya Chervenyashka, Snezhana Dimitrova, Nasya Nenova, Valentina Siropulo, Kristiana Valcheva, and a Palestinian doctor, Ashraf Ahmad Jum'a, in Tripoli. The six face death-penalty charges of deliberately infecting 426 children with HIV at al-Fateh Children's Hospital in Benghazi in 1998. Strong scientific evidence is needed to establish the cause of this infection. However, independent science-based evidence from international experts has so far not been permitted in court.

Libya is currently making efforts to join the community of peaceful nations by renouncing weapons of mass destruction and adhering to international standards regarding the rule of law. This trial is another opportunity for Libya to demonstrate its commitment to recognized values and norms. But so far Libya has failed to follow the norms of international justice in the case of the charged medical workers.

We appreciate the agony and the sadness of the parents of these children and we sympathize with the difficult situation of the Libyan authorities in trying to deal with this matter. However, we feel that if justice is to be served it is essential that the defence should be permitted to present its case.

Among the disallowed scientific evidence is a 2003 report, which Libya requested, and which was provided by Luc Montagnier, a co-discoverer of the virus that causes AIDS, and Italian microbiologist Vittorio Colizzi. The report concluded that the infection at the hospital resulted from poor hygiene and reuse of syringes, and also that the infections began before the arrival of the nurses and doctor in 1998.

On 29 August 2006, a Libyan prosecutor reiterated the call for the six to be given the death penalty. The next, and probably last, court hearing is scheduled for the 4 November, with a verdict expected shortly thereafter. A miscarriage of justice will take place without proper consideration of scientific evidence. We urge the appropriate authorities to take the necessary steps to permit such evidence to be used in this case.
To uphold justice, and ensure a fair trial, we affirm the need for:

\begin{abstract}
- Defence lawyers to have the right to call and examine witnesses on the health workers' behalf under the same conditions as witnesses called against them, and
\end{abstract}

- The appropriate authorities to call upon internationally recognized experts in AIDS research to examine and testify on the evidence as to the cause of the HIV infections in the children.

Yours sincerely,

Richard J. Roberts ${ }^{\star}$ and 113 fellow Nobel

Laureates $\dagger$

† 1993 Nobel Laureate in Physiology ar Medicine, Chief scientific officer, New England Biolabs, 240 County Road, Ipswich, MA 01938-2723, USA $\dagger A$ full list of signatories to this letter is available as supplementary information at www.nature. com/nature/journal/v444/n7116/suppinfo/ 444146a.html.

Published online 2 November 2006.

\section{Don't forget the steps that led physics to where it is}

SIR - In your News story ${ }^{\alpha}$ Neutrinos make a splash in Italy" (Nature 443, 126; 2006), you highlight a project, " first sketched out 25 years ago", to attempt to discover whether neutrinos have mass.

As president of the National Institute for Nuclear Physics from 1977 to 1983 , what I presented to the Italian authorities 27 years ago, far from being a 'sketch', was a full project. It had a set of scientific goals, including the neutrino oscillations from the 'artificial' source located at the CERN particle-physics lab, where, in the early 1960 s, the search for the third lepton was intensively carried out using the hypothesis of the third neutrino, now called 'tau,' but originally called heavy lepton neutrino.' This is the neutrino which, as envisaged in the original proposal, will be the result of the 'oscillation' from the neutrinos beamed underground from CERN and searched for at Gran Sasso with the OPERA detector.

The scientific programme for the Gran Sasso project was so complete when first proposed that, even now, no new item has been added. An additional detail not reported in your news story is that the best detector working at Gran Sasso is at present the Large Volume Detector set up to study cosmic neutrinos - a powerful liquid scintillator and tracking device, which has been in full operation for more than 10 years. A detailed study of the time correlation and of the neutrino beam structure indicates that the neutrino beam works exactly as designed.

"Without memory there is no civilization and no physics," as Enrico Fermi used to say. Antonino Zichichi

National Institute for Nuclear Physics, Via Enrico Fermi, 40-00044 Frascati, Rome, Italy

\section{Biodiversity definitions vary within the discipline}

SIR - R. M. Ewers and A. S. L. Rodrigues, in Correspondence ( ${ }^{\alpha}$ Speaking different languages on biodiversity" Nature 443, $506 ; 2006$ ), raised the issue of vocabulary differences between conservation biologists and economists, a problem that has long been recognized by biodiversity scientists.

We carried out an informal email survey of different disciplines and stakeholders involved in biodiversity conservation, asking people to define terms such as biodiversity, ecosystem function and ecosystem goods and services. We received 25 responses. The definitions varied hugely, not only between ecologists and economists, but also between them and policy-makers. Most alarming is that the definitions varied among the 13 ecologists who responded. Although this is a small sample, they were all high-profile scientists and the results were surprising.
When defining biodiversity, for example, seven used that of the Convention on Biological Diversity, two used species richness and four used other definitions.

To create solutions for biodiversity loss, it is essential for natural and social scientists to overcome such language barriers. But for this to be of any use, scientists also need to become much better at communicating their findings to policy-makers, and understanding from them the science knowledge that is required to make policy. Alison Holt bioSUSTAINABILITY International Project Office, University of York, Heslington, York Y010 5DD, UK

\section{US scorn for treaties hasn't improved nuclear security}

SIR - Your Editorial “A global folly" (Nature 443,$605 ; 2006$ ) states that scientists working on disarmament and anti-proliferation issues "have looked on aghast as disarmament sceptics around the world have scorned the value of international treaties. To my knowledge, there was initially only one country scornfully spreading scepticism on, among others, the Comprehensive Nuclear Test Ban Treaty and the Non-Proliferation Treaty. That was the United States of America. Sebastian Raupach

Institute of Atmospheric Physics, Johannes Gutenberg University, 55099 Mainz, Germany 